\title{
CRISE, DESENVOLVIMENTO E TERRITÓRIO: REFLEXÕES SOBRE O EXTREMO OESTE DA REGIÃO METROPOLITANA DO RIO DE JANEIRO
}

\author{
Leandro Dias de Oliveira ${ }^{1}$ \\ ORCID http://orcid.org/0000-0001-7257-0545
}

André Luiz Nascimento Germano ${ }^{2}$

ORCID https://orcid.org/0000-0003-4265-4320

Miguel Alexandre do Espírito Santo Pinho ${ }^{3}$

ORCID https://orcid.org/0000-0002-8832-117X

Recebido em: 31 mar. 2021

Publicado em:28 abr. 2021

\section{RESUMO}

O objetivo deste artigo é, a partir dos conteúdos da geografia econômica e da economia política, analisar os limites do modelo de desenvolvimento instituído nas últimas décadas nas cidades do extremo oeste da Região Metropolitana do Rio de Janeiro, formado pelos municípios de Seropédica, Paracambi, Queimados, Japeri e Itaguaí (integrada ao Distrito Industrial de Santa Cruz). A reestruturação territorial-produtiva dessas cidades incluiu a implementação de novos empreendimentos do ramo industrial e logístico, tornando a região numa área de expansão direta, influência e propagação política, econômica, social, cultural e ambiental da metrópole. Questionando o modelo de desenvolvimento instituído e fazendo uma análise crítica dos últimos anos, são apresentadas provocações acerca da construção de um modelo de desenvolvimento social para a região.

PALAVRAS-CHAVE: Desenvolvimento. Reestruturação territorial-produtiva. Geografia Econômica. Região Metropolitana do Rio de Janeiro.

\section{CRISIS, DEVELOPMENT AND TERRITORY: REFLECTIONS ON THE FAR WEST OF THE METROPOLITAN REGION OF RIO DE JANEIRO}

\footnotetext{
${ }^{11}$ Professor Associado do Departamento de Geografia da Universidade Federal Rural do Rio de Janeiro UFRRJ, Campus Seropédica. Licenciado em Geografia pela UERJ-FFP, Mestre em Geografia pela UERJ, Doutor em Geografia pela UNICAMP e Pós-doutor em Políticas Públicas e Formação Humana pela UERJ. ${ }^{2}$ Mestre pelo Programa de Pós-graduação em Geografia (PPGGEO) da Universidade Federal Rural do Rio de Janeiro (UFRRJ, 2020), na linha de pesquisa "Espaço, Política e Planejamento". Membro da linha de pesquisa Reestruturação Econômico-Espacial Contemporânea, vinculada ao Laboratório de Geografia Econômica e Política (LAGEP), no Departamento de Geografia da UFRRJ.

${ }^{3}$ Mestre em Geografia pela Universidade Federal Rural do Rio de Janeiro (UFRRJ) e doutorando em Geografia pela Universidade do Estado do Rio de Janeiro (UERJ). Membro da linha de pesquisa Reestruturação Econômico-Espacial Contemporânea, vinculada ao Laboratório de Geografia Econômica e Política (LAGEP), no Departamento de Geografia da UFRRJ.
} 


\section{ABSTRACT}

The objective of this article is, based on the economic geography and the political economy, to analyze the limits of the development model instituted in the last decades in the cities localized in the extreme west of the from the Metropolitan Area of Rio de Janeiro, formed by the cities of Seropédica, Paracambi, Queimados, Japeri and Itaguaí (integrated with the Industrial District of Santa Cruz). The territorial-productive restructuring of these cities included the implementation of new industrial and logistical projects, making this region as direct expansion area of influence and propagation of Metropole, in questions political, economic, social, cultural and environmental. Questioning the development model established and making a critical analysis of the last years, provocations about the construction of a model of social development for the region are presented.

KEYWORDS: Development. Territorial-Productive Restructuring. Economic Geography. Metropolitan Area of Rio de Janeiro.

\section{INTRODUÇÃO}

Nos últimos vinte anos assistimos a profundas mudanças na geografia econômica da Região Metropolitana Fluminense. A cidade do Rio de Janeiro se consolidou definitivamente como centro de serviços e negócios, especialmente na condição de espaço para realização de grandes eventos - em particular, os esportivos, adotando as características da urbanização turística-olímpica-esportiva ${ }^{4}$ - e processos de segregação valorização imobiliária (BOTELHO, 2013). Ao mesmo tempo, as franjas da Região Metropolitana do Rio de Janeiro viveram uma espécie de revolução industrial intempestiva, com a projeção de uma espécie de cinturão industrial metropolitano por meio de um profundo processo de reestruturação territorial-produtiva (OLIVEIRA, 2015 e 2020).

Revolução industrial é, evidentemente, um termo genérico e complexo, mas esteve presente nos anúncios locais de $\operatorname{prefeituras~}^{5}$ que saudavam a chegada de novas unidades fabris. Outrossim, a reestruturação é, de maneira imbricada, produtiva, pois envolve as transformações contemporâneas da produção fabril (produção just-in-time, volatilização do trabalho, formas consorciadas de manufaturação, etc.), e territorial, com a emersão de um espaço com novas relações de poder, de urbanização e de uso de território, com mecanismos de governança público-privada, urbanização rarefeita e

\footnotetext{
${ }^{4}$ Consultar: MASCARENHAS, 2014; MASCARENHAS, BIENENSTEIN, SANCHEZ, 2011. Sobre urbanização turística, também indicamos: MASCARENHAS, OLIVEIRA, RAMÃO, 2020.

${ }^{5}$ Foi o caso de Seropédica, conforme: OLIVEIRA, 2016.
} 
localização de plantas industriais em esconderijos espaciais (OLIVEIRA, 2015), bem como de potencialização do complexo porto-indústria (PESSANHA, 2017; PESSANHA, GOMES FILHO, QUINTO JÚNIOR, OLIVEIRA, 2014), e das redes logísticas.

Em especial, nas cidades localizadas nas franjas metropolitanas da Região Metropolitana do Rio de Janeiro emergiram novas economias de aglomeração industrial.

A instalação do Complexo Petroquímico do Rio de Janeiro (Comperj, rebatizado de Polo GasLub Itaboraí) na parte leste da região metropolitana do Rio de Janeiro (Grande Niterói) era o símbolo máximo do período: integrando rodovias, um porto específico e outras estruturas produtivas, especialmente nas cidades de Itaboraí, São Gonçalo e Maricá (OLIVEIRA, 2018; CANDIDO, 2019), se tornaria um importante vetor de desenvolvimento, em particular pela integração por meio do Arco Rodoviário Metropolitano (TINOCO, 2019) com o polo de desenvolvimento da Refinaria Duque de Caxias (Reduc-Petrobrás), situada no eixo da BR-040 na cidade de Duque de Caxias, e finalmente com o Porto de Itaguaí, em um verdadeiro complexo portuário-siderúrgicoindustrial situado na Baía de Sepetiba ${ }^{6}$. Tais investimentos se constituíram em um marco no processo de recuperação da economia no estado e na delimitação de novas territorialidades no Rio de Janeiro e foram indutores da reversão de um quadro de relativo esvaziamento das atividades econômicas indústrias na Região Metropolitana (OLIVEIRA, F.; OLIVEIRA, L; 2020). Em cidades com feições muito rurais, como o caso de Seropédica, os novos aportes logísticos passaram a atrair importantes empresas para os seus limites, constituído novas redes que se comunicam e contagiam para além do próprio espaço metropolitano.

Todavia, este processo ficou aquém de significar grandes melhorias para a população do entorno, tanto pela geração insuficiente de postos de trabalho, mas também pelos próprios impactos ambientais e parcas implicações sociais positivas. Eis o objetivo deste central artigo: aproximando os olhares da geografia econômica e da economia política - e, importante insistir, também da ecologia política -, a intenção é refletir sobre

\footnotetext{
${ }^{6}$ De acordo com Perdigão (2015), a Baía de Sepetiba é um ambiente aquático de transição entre rio e mar, com $447 \mathrm{~km}^{2}$ de área. Suas águas estão em três municípios fluminenses: o município do Rio de Janeiro, nos bairros de Barra de Guaratiba, Pedra de Guaratiba, Sepetiba e Santa Cruz; o município de Itaguaí; e o município de Mangaratiba. É composta por sub-bacias hidrográficas que envolvem 15 municípios do Estado do Rio de Janeiro: Seropédica, Queimados, Engenheiro Paulo de Frontin, Japeri, Paracambi, Miguel Pereira, Mangaratiba, Vassouras, Barra do Piraí, Mendes, Nova Iguaçu, Piraí, Rio Claro e os já citados Rio de Janeiro e Itaguaí.
} 
os desafios inerentes ao modelo de desenvolvimento instituído nas últimas décadas por meio um breve balanço crítico; e, a partir dessa análise, apresentar algumas proposições, ainda que de forma ensaística, para a construção de um modelo de desenvolvimento social para a região.

\section{As mudanças produtivas no Extremo Oeste Metropolitano do Rio de Janeiro}

O Brasil viveu um ciclo expansivo de sua economia, com crescimento acima da média da década de 1990, entre 2004 até 2014, e aumento dos investimentos públicos e privados. O Partido dos Trabalhadores governou o país de 2003 a 2016, vencendo quatro disputas presidenciais seguidas e tendo o último mandato eleito, o da presidente Dilma Rousseff, sido interrompido por um golpe de estado disfarçado de impeachment - um golpe jurídico-parlamentar ou ainda um golpeachment (SOUZA, 2017). Esse período de gestões do PT foi chamado de neodesenvolvimentista (BOITO JÚNIOR, 2015), de novo desenvolvimentismo (MERCADANTE, 2010) e social-desenvolvimentismo (POCHMANN, 2010) por analistas que viam uma inflexão em maior ou menor grau do neoliberalismo aplicado desde 1990 e maior estímulo a um modelo de desenvolvimento de matriz nacional com maiores preocupações sociais.

É neste contexto que veremos a emersão do Extremo Oeste Metropolitano (EOM), formado por uma parcela dos munícipios da Baixada Fluminense que passaram por um processo de reestruturação regional com características comuns: Queimados, Japeri, Paracambi, Seropédica e Itaguaí - este último, sempre pensado de maneira contígua ao Distrito Industrial de Santa Cruz (OLIVEIRA, 2015) (Ver Mapa 1). Os municípios que formam o EOM conformaram um recorte regional a partir das transformações comuns que sofreram no processo de reestruturação contemporâneo, baseadas especialmente nos recentes aportes industriais e logísticos, e não por relações históricas de integração econômica como o restante da Baixada Fluminense.

Neste sentido, buscamos segmentar o espaço metropolitano em áreas específicas: leste metropolitano, influenciado pela economia do petróleo e sob a influência de fóruns econômicos e administrativos, como o Conleste e o Fórum Comperj; o centro da Baixada Fluminense, cuja territorialidade se altera com as novas perspectivas de circulação viária, tanto pela Rodovia Presidente Dutra (Rio - São Paulo) quanto pelo Arco 
Metropolitano, que corta o município de Nova Iguaçu e o interliga aos demais municípios metropolitanos sem passar pela cidade do Rio de Janeiro; a área portuária no município de Itaguaí (ou extremo oeste metropolitano fluminense), que produz uma retroárea com perspectiva industrial ao longo do Arco Metropolitano e que se estende pelos municípios de Seropédica, Japeri, Queimados e Paracambi; e a cidade do Rio de Janeiro, marcada por investimentos para abrigar megaeventos e turismo e para atualizar suas funções e status de centro de gestão de negócios (OLIVEIRA, OLIVEIRA, 2020) (Ver Mapa 1).

\section{Mapa 1 - Complexidades sub-regionais do espaço metropolitano do Rio de Janeiro}

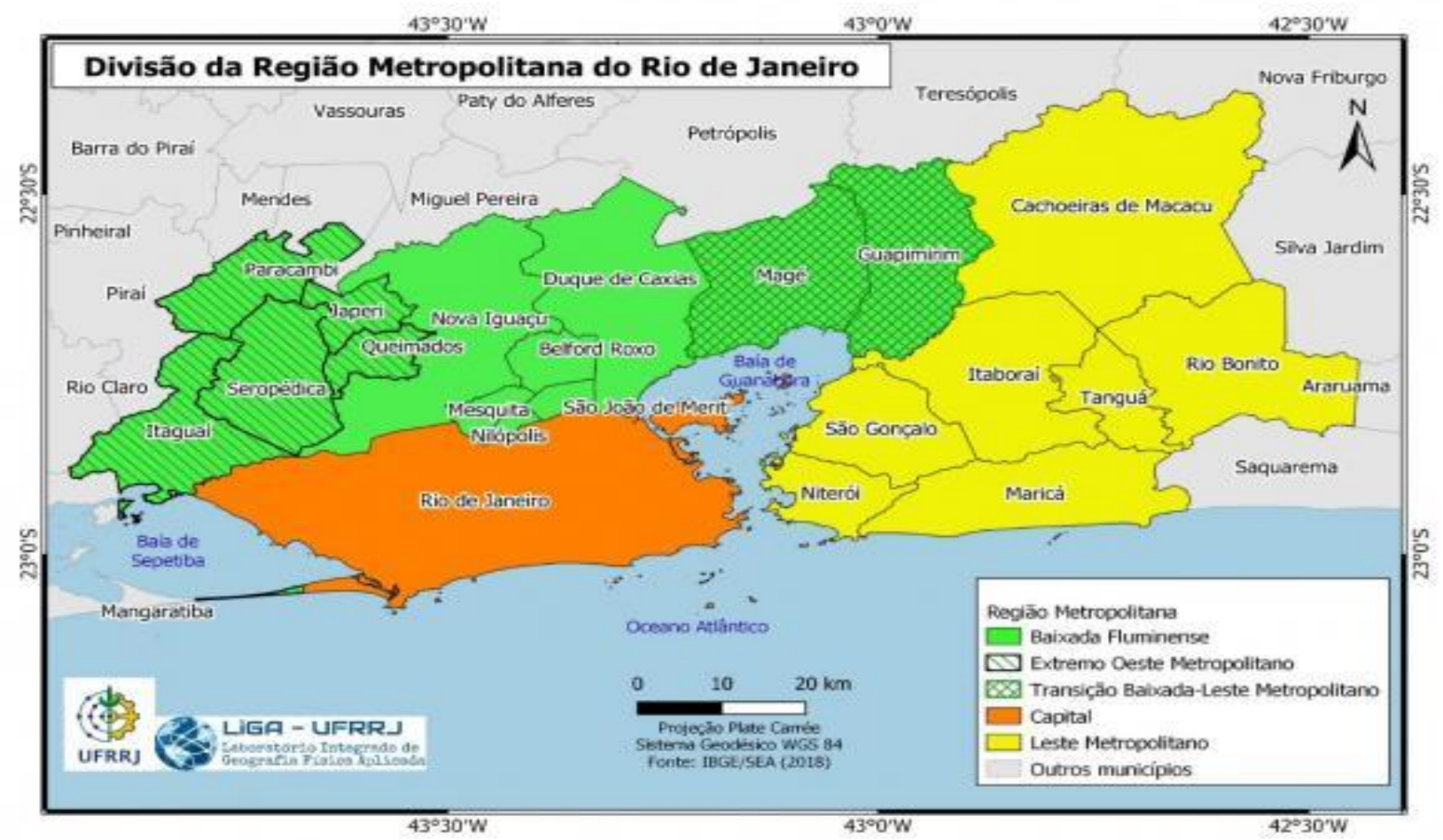

Fonte: Oliveira, L.D. de (2020a).

Embora o processo de industrialização nessas cidades remeta a momentos anteriores e não sejam inteiramente novos, há um novo impulso em curso gerado pelo crescimento econômico fluminense e nacional, que causa transformações espaciais significativas. $\mathrm{O}$ espraiamento dos investimentos nesses territórios também foram fruto de um processo de articulação política e de políticas públicas visando atração de empresas. Soja demonstra que um processo em que o capital busca por novos espaços mais vantajosos do ponto de vista da acumulação podem levar a "inversões de papel das regiões", na medida em que áreas industriais antes prósperas vão declinando de forma 
simultânea à rápida industrialização de periferias regionais antes menos desenvolvidas (SOJA, 1993 [1989] p. 193).

Esse processo está diretamente ligado à expansão da economia fluminense e o espraiamento metropolitano das atividades econômicas, mais especificamente nesse caso, para as suas bordas, com o surgimento de novas economias de aglomeração urbana, reconstituindo os novos empreendimentos produtivos como centralidades urbanas e requalificando a indústria como vetor de progresso em áreas mais pobres (OLIVEIRA, 2015). Mesmo com a heterogeneidade histórica das relações entre essas cidades da região, o elemento em comum é questão produtiva-logística e o próprio processo de reestruturação regional:

O que aproximou Itaguaí, Seropédica, Paracambi, Queimados e Japeri foi o trunfo territorial produtivo-logístico. São cidades com histórias diferentes: Itaguaí pertence historicamente ao bloco regional da Costa Verde; Seropédica foi emancipada de Itaguaí apenas em 1995; Paracambi é uma cidade formada pela integração de partes emancipadas dos municípios de Vassouras e Itaguaí, no ano de 1960; por sua vez, Queimados e Japeri possuem histórias mais próximas à Baixada Fluminense strictu sensu, emancipadas de Nova Iguaçu respectivamente em 1990 e 1991(OLIVEIRA, 2020, p. 8).

A ascensão do Extremo Oeste Metropolitano esteve diretamente relacionada à conjuntura de crescimento econômico para além da capital mediante a intenção de criar uma espécie de novo caminho do desenvolvimento. Nesse sentido, esse novo caminho do desenvolvimento, visibilizado com a construção do Arco Rodoviário Metropolitano, teve um impacto muito grande em espaços outrora muito isolados e distantes do centro urbanometropolitano do município do Rio de Janeiro. Nota-se, portanto, uma complexidade muito maior ao tratar da Baixada Fluminense, pois as cidades do EOM são mais distantes e com problemas diferentes daquelas historicamente que compõem a Baixada Iguaçuana (ROCHA, 2014), centralizadas pelas grandes cidades de Nova Iguaçu e Duque de Caxias.

Itaguaí, Seropédica, Paracambi, Queimados e Japeri compõem, preliminarmente, a periferia da periferia, com diferentes ritmos e realidades quando comparadas com o restante da Baixada Fluminense. Todavia, essa "Segunda Baixada" tem apresentado importantes fricções e linkages produtivos com outras partes da Região Metropolitana do Rio de Janeiro, tanto da Baixada Fluminense quanto com a própria capital, especialmente com sua porção contígua - a Zona Oeste -, além do Médio Vale Paraíba Fluminense, 
entendido aqui não apenas como trilha para São Paulo, mas também a partir de um espectro megarregional que permita aproximar as duas metrópoles nacionais em apenas uma nebulosa metropolitana (LENCIONI, 2015).

As transformações nessas cinco cidades têm se revelado muito potentes com as mudanças produtivas recentes por meio de uma dinâmica econômica de fluxos muito intensos, com empresas de grande porte atuando em cidades que não possuíam tais aportes e cuja urbanização ainda é recente ${ }^{7}$. São fortalecidos, portanto, os condomínios logísticos que espocam nas estradas principais e mesmo nas de menor tráfego (respectivamente, Rodovia Presidente Dutra [BR-116] e Rodovia Ary Schiavo [RJ-125] são exemplos significativos); grupos internacionais se instalam em estradas vicinais (como o Grupo Saint-Gobain, mediante a instalação da unidade da Brasilit, na Estrada Santa Alice, em Seropédica); complexos siderúrgicos ficam situados no limite da região (como a Ternium-CSA, no bairro de Santa Cruz, na cidade do Rio de Janeiro) e distritos industriais são redinamizados, como os casos de Queimados e Santa Cruz, criados na década de 1970.

No eixo Santa Cruz-Itaguaí, por meio dos financiamentos Banco Nacional do Desenvolvimento Econômico e Social (BNDES), de isenções fiscais e da construção da infraestrutura necessária, como energia elétrica subsidiada, abertura de estrada e construção de portos, ocorreu a instalação de novos empreendimentos e redinamização dos próprios fluxos de mercadorias. Somente na Ternium-CSA, localizada no limite do bairro de Santa Cruz e de Itaguaí, quando somados o financiamento do banco com os valores relativos a todas as isenções fiscais de todas as esferas do Estado brasileiro, chegase à cifra de $\mathrm{R} \$ 5$ bilhões de recursos públicos investidos (MOURA, RODRIGUES, 2018). Após o começo das obras da Ternium, em 2006, os processos de licenciamento dos seguintes projetos foram iniciados nesta mesma região: a construção de um grande porto e estaleiro para a construção de submarinos da Marinha do Brasil; o Porto Sudeste, então pertencente à LLX Logística; a expansão da capacidade produtiva da Gerdau Cosigua e a construção da nova usina de aços especiais; a ampliação do Porto de Itaguaí; e a edificação de um gigantesco porto compartilhado entre Petrobras, Gerdau e CSN (PACS, 2009). Todos esses planos realizados com base na exploração de riquezas

\footnotetext{
${ }^{7}$ Para um aprofundamento detalhado dos espaços industriais existentes no Extremo Oeste Metropolitano Fluminense. Cf.: OLIVEIRA, 2015.
} 
naturais, em particular commodities agrícolas e minerais ${ }^{8}$. O porto de Itaguaí se firmou progressivamente como exportador de minério e produtos siderúrgicos, se consolidando com um verdadeiro vetor da globalização (SANTOS; SILVEIRA, 2001) ${ }^{9}$.

\section{O desenvolvimento para além da questão eminentemente econômica}

É cada vez mais urgente que se compreenda o desenvolvimento para além da face estritamente econômica e que seu significado extrapole a vinculação com as noções de modernização, crescimento e progresso econômico. Limitar o desenvolvimento à acumulação de riquezas, à expansão geográfica do modelo civilizacional, à artificialização do espaço e à ruptura com ambiente rural-natural também são limitadores interpretativos e ideológicos do termo.

O desenvolvimento que prezamos deve ter como princípios e objetivos gerais: a satisfação das necessidades humanas; a capacidade de potencializar o gênio inventivo e as liberdades intelectuais; a não obliteração a natureza como "recurso" e o respeito e preservação das formas comunitárias de produção tradicional; e o zelo às liberdades, à democracia e à justiça social. À luz da geografia, o desenvolvimento deve ser multiescalar e capaz de promover o diálogo com a comunidade, com o entorno imediato e com a região; há que ser processo social e não fim em si mesmo, numa construção coletiva, democrática e dialógica.

Parecem observações simples, mas, em meio a este grande aporte de investimentos produtivos e logísticos e surgimento concomitante de condomínios luxuosos que atenderam somente às classes médias, os grupos tradicionais precisaram

\footnotetext{
${ }^{8} \mathrm{O}$ eixo Santa Cruz - Itaguaí-RJ se consolidou como um polo de atividades portuárias-industriais de grande magnitude e altíssimo dinamismo. Há um imenso parque industrial e um complexo portuário voltado para a exportação de commodities minerais e produtos siderúrgicos neste eixo do extremo oeste da Região Metropolitana do Rio de Janeiro (OLIVEIRA, 2015). No bairro carioca Santa Cruz funciona um Distrito Industrial que foi inaugurado nos anos de 1970 (DAMAS, 2008) como consequência de projetos que calcaram na indústria e no desenvolvimentismo a política nacional, além de forte influência do contexto global de expansão geográfica do capitalismo (BOTELHO, 2014). Na mesma conjuntura, para atender demandas, entre outros, deste distrito industrial, o atual Porto de Itaguaí, inicialmente chamado de Porto de Sepetiba, foi construído como um dos importantes investimentos em infraestrutura daquele momento, na busca de facilitar as dinâmicas de expansão do capital e da globalização crescente.

9 O conglomerado industrial-siderúrgico-portuário instalado em Santa Cruz possui usina siderúrgica integrada, usina termoelétrica e um porto, com dois terminais (PACS, 2012). A presença de portos e as redes ferroviárias trazem um embate de lógicas econômicas baseadas em sistemas técnicos distintos, com as atividades siderúrgicas impondo normas às atividades pesqueiras, antes característica tradicional da região da Baía de Sepetiba.
} 
enfrentar o desenvolvimento, entendido com um duro e opressor processo de modernização. Não há dúvida que nesta periferia da periferia sobrevivem populações periferizadas, que não participam da celebração e tampouco usufruem das benesses do modelo (OLIVEIRA, 2020). O enorme terminal portuário da Ternium-CSA, na Baía de Sepetiba, por exemplo, avança $4 \mathrm{~km}$ no mar e impede que os mastros dos barcos dos pescadores passem por debaixo da ponte; destarte, para trafegar de um ponto ao outro em uma área onde tradicionalmente circulavam livremente, os pescadores precisam contornar a construção (PACS, 2012). Da mesma maneira, a poluição e os impactos na costa de um complexo portuário-siderúrgico de grande porte consolidaram tanto a Baía quanto a Baixada de Sepetiba como verdadeiros paraísos de poluição, ou zonas de sacrifício e áreas de injustiças ambientais (OLIVEIRA, 2020). Os impactos, denúncias, imbróglios e disputas revelam o embate entre lógicas com base técnica e escalas geográfica distintas ${ }^{10}$.

Da mesma maneira que a questão socioambiental, é possível pensar o modelo de desenvolvimento empreendido no EOM a partir da questão da oferta de empregos. Preliminarmente, é oportuno apontar que o modelo brasileiro de desenvolvimento gerou um processo interessante no mercado de trabalho: o Brasil teve um saldo positivo muito elevado nos empregos até 2 salários mínimos e um saldo negativo de postos de trabalho de mais de 2 salários mínimos. Isto é visível no gráfico 1.

\section{Gráfico 1 - Empregos gerados abaixo e acima de 2 salários mínimos (x 1.000)}

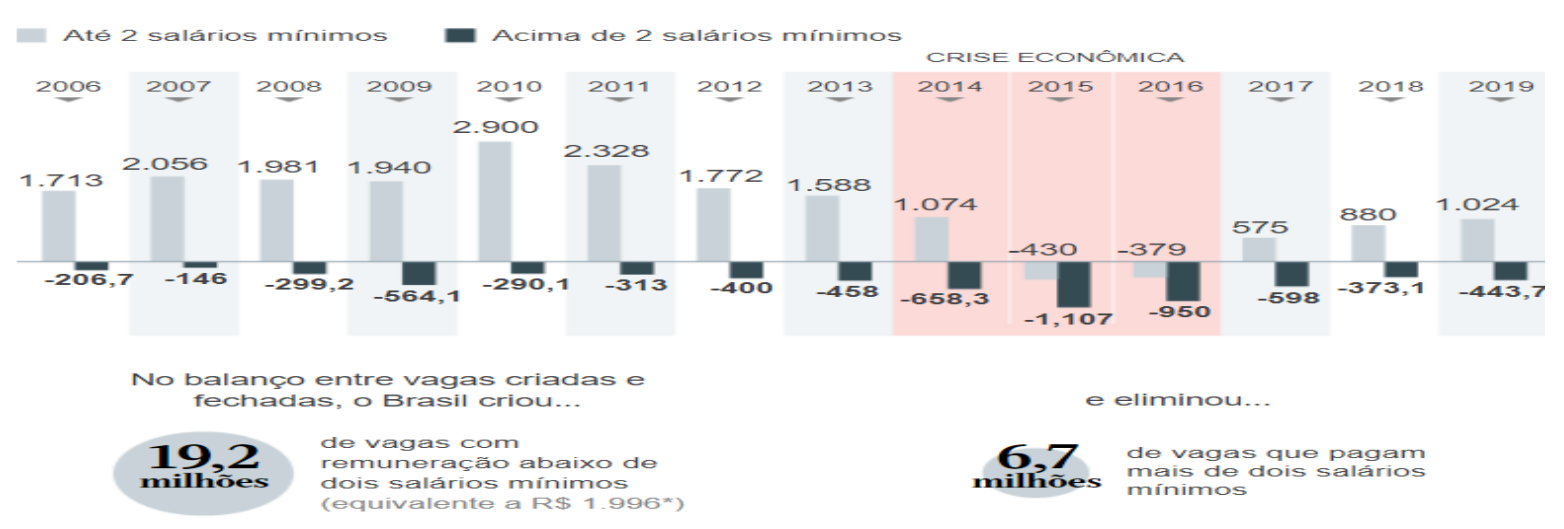

Fonte: CAPETTI, 2020 (Dados CAGED).

\footnotetext{
${ }^{10} \mathrm{O}$ próprio acesso da população de Santa Cruz a políticas públicas voltadas para direitos básicos está entre os mais precários do município do Rio de Janeiro. A aparição de moradores de Santa Cruz em jornais televisionados, por exemplo, quase sempre vem acompanhada de cobranças por esgotamento sanitário, água tratada, asfalto, ar limpo, medicamentos, merenda e material escolar em aparelhos públicos (PACS, 2012; GERMANO, 2020).
} 
O gráfico 1 demonstra uma tendência de eliminação de vagas de trabalho que ganham acima de 2 salários mínimos e a substituição por ocupações que ganham até 2 salários mínimos. Pelo volume muito discrepante entre os empregos gerados e os postos eliminados, entendemos que não se trata apenas de um rebaixamento salarial dos já empregados ou substituição por outros funcionários recebendo menos. O que temos é uma mudança no perfil das ocupações, pois, os setores dinâmicos que alavancaram o crescimento do emprego no emprego no Brasil nos anos recentes, de acordo com Gala (2017) e Carvalho (2018), se deram pelo aquecimento do mercado interno e por meio da expansão de serviços simples, que possuíam o consumo deprimido por causa da baixíssima renda de uma parcela muito significativa da população no país.

Não é possível um crescimento autossustentado desses setores sem a política contínua de expansão da renda dos mais pobres e gastos públicos que mantenham o aquecimento econômico. Sem o desenvolvimento de um setor industrial ligado à indústria de transformação de alta produtividade e serviços complexos dela derivados, não encontraremos meios de gerar empregos mais bem remunerados. Não há cogitação de se pagar salários mais altos em setores que há pouca ou nenhuma capacidade de intensificação da produtividade do trabalho com a inserção de novas tecnologias, uma vez que com a ausência de ganhos de escala, necessitam contratos empregados com baixos salários para aumentar a competitividade e seus lucros. Com a redução de ritmo do crescimento da economia chinesa comprimindo drasticamente os preços das commodities, já no final de 2014 o governo brasileiro optou por um duro ajuste fiscal, derrubando investimentos e gastos discricionários, que ampliou o cenário de crise econômica.

Assim, de maneira geral, o perfil dos empregos gerados em tempos de desenvolvimento do EOM foi de baixa remuneração e ligados a serviços pouco complexos (PINHO, 2021). Em Queimados, onde vislumbrou-se um modelo de crescimento que inspiraria outras prefeituras, mesmo a forte participação da indústria na economia gerou ocupações com remunerações modestas, dentro do perfil dos empregos gerados no Brasil em setores menos dinâmicos da economia. Os baixos salários pagos na indústria queimadense são um indício de baixa produtividade desses segmentos instalados no município, com poucos investimentos em inovação. A indústria local também não foi 
capaz de gerar na cidade a instalação de serviços sofisticados, como engenharia, marketing, programação, informática, serviços contábeis e jurídicos que pudessem pagar salários mais elevados e reter mais renda circulando na cidade. Se os serviços mais simples são executados nas cidades vizinhas mais encorpadas por densidades empresariais, atividades de grande fôlego instrumental e tecnológico são provavelmente executados em grandes centros, como as cidades do Rio de Janeiro e São Paulo.

Analisando a renda média dos trabalhadores nas cinco cidades que compõe o EOM, é possível compreender as tendências de acréscimo ou não da renda dos trabalhadores na região em meio aos bons ventos econômicos a partir de 2010 e do período de crise que se inicia na virada de 2014 para 2015 (Ver: Tabela 1).

Tabela 1 - Média dos rendimentos em salários mínimos no Extremo Oeste Metropolitano do Rio de Janeiro

\begin{tabular}{c|c|c|c|c|c|}
$\mathbf{A n o}$ & \multicolumn{1}{c}{ Queimados } & Japeri & Paracambi & Seropédica & Itaguaí \\
\hline $\mathbf{2 0 1 0}$ & 2,4 & 2 & 1,8 & 4,1 & 3 \\
\hline $\mathbf{2 0 1 1}$ & 2,4 & 2,1 & 4 & 4 & 3,2 \\
\hline $\mathbf{2 0 1 2}$ & 3,1 & 2 & 3,5 & 3,8 & 3,4 \\
\hline $\mathbf{2 0 1 3}$ & 2,6 & 2,1 & 1,8 & 4,2 & 3,5 \\
\hline $\mathbf{2 0 1 4}$ & 2,4 & 2 & 1,9 & 4,3 & 3,5 \\
\hline $\mathbf{2 0 1 5}$ & 2,4 & 2,1 & 1,9 & 3,9 & 3,4 \\
\hline $\mathbf{2 0 1 6}$ & 2,3 & 2 & 1,7 & 3,8 & 3,3 \\
\hline $\mathbf{2 0 1 7}$ & 2,3 & 2,1 & 1,8 & 4 & 3,1 \\
\hline $\mathbf{2 0 1 8}$ & 2,4 & 2,1 & 1,9 & 4,1 & 3,1 \\
\hline
\end{tabular}

Fonte: IBGE Cidades (Organização: Miguel Pinho).

Em que pese uma participação significativa de atividades industriais nas cidades do EOM, observamos que os momentos de aumento significativo das médias salariais ocorrerem apenas em duas cidades, Queimados e Paracambi. Em Queimados, observamos no ano de 2012 a renda média subir de 2,4 salários para 3,1; no ano subsequente, ainda manteve valor ligeiramente superior, sendo de 2,6, quando a partir de 2014 retorna ao patamar de 2,4 e 2,3 salários. Paracambi teve uma excepcionalidade da renda média nos anos de 2011 e 2012, aumentado de 1,8 para 4 salários, depois uma redução para 3,5, e retornando ao patamar anterior a partir de 2013. Em Japeri a renda 
oscilou entre 2 e 2,1 salários ao longo desses nove anos e se observou mudanças significativas. Seropédica manteve uma renda elevada, fato este mais ligado à existência do campus-sede da Universidade Federal Rural do Rio de Janeiro como fator de atração de professores e técnicos para habitarem em seus limites do que pela pujança de atividades fabris, encontrando uma irregularidade no padrão acréscimo e decréscimo da renda ao longo dos anos analisados. Itaguaí vivenciou nos anos de 2014 e 2015 o ápice da renda em salários mínimos, mas logo retomou a valores próximos ao patamar de 2010.

Podemos observar que em todo o EOM, em que pese anos diferentes em cada cidade em que os trabalhadores aferiram rendas melhores, observamos que em todos os municípios se retornou aos patamares próximos aos 2010 em 2018, não sendo possível verificar uma melhora significativa da renda média das pessoas na cidade.

Para compreensão mais apurada dos impactos limitados no emprego no EOM entre os anos de 2009 e 2019, coletamos dados disponíveis no Cadastro Geral de Empregados e Desempregados (CAGED), catalogando o saldo entre admissões e desligamentos entre os anos analisados em todos os municípios pertencentes ao EOM (Ver Tabela 2). Isto serve para observar a perenidade das transformações produtivas e seus impactos no mercado de trabalho, que é o elemento mais sensível para a população fruto intensificação das atividades econômicas. O CAGED analisa somente as movimentações no mercado de trabalho formal e exclui os postos de trabalho de regime estatutário; apenas os trabalhadores celetistas são contabilizados.

\section{Tabela 2 - Saldos de admissões e desligamentos nos setores industriais no Extremo Oeste Metropolitano 2009-2019}

\begin{tabular}{|c|c|c|c|c|c|c|}
\hline \multirow{2}{*}{ Município } & \multicolumn{2}{|c|}{ Extrativismo mineral } & Indústria de transformação & \multicolumn{2}{c|}{ Construção civil } \\
\cline { 2 - 7 } & Admissões & Desligamentos & Admissões & Desligamentos & Admissões & Desligamentos \\
\hline Queimados & 372 & 377 & 10.604 & 10.511 & 16.929 & 11.842 \\
\hline Japeri & 111 & 111 & 4.389 & 4.106 & 1.424 & 1.323 \\
\hline Itaguaí & 814 & 954 & 13.466 & 12.286 & 39.698 & 39.285 \\
\hline Seropédica & 1.592 & 1.699 & 4.076 & 3.893 & 8.906 & 7.889 \\
\hline Paracambi & 30 & 20 & 4.414 & 4.175 & 637 & 764 \\
\hline Saldo & \multicolumn{2}{|c|}{-242} & \multicolumn{2}{|c|}{1978} & & 6411 \\
\hline
\end{tabular}

\footnotetext{
Fonte: CAGED (Organização: Miguel Pinho).
} 
O primeiro apontamento é dos números modestos de admissões na indústria extrativista em todo EOM, tendo alguma relevância apenas em Seropédica e Itaguaí, mas o que vimos é que houve uma retração entre o número de empregados. A indústria de transformação teve um saldo modesto de menos de 2 mil novas vagas. Itaguaí obteve o maior saldo em admissões e desligamentos, respondendo por mais da metade do saldo final da região, e teve um montante grande de admissões ao lado de Queimados. Os dois municípios são os principais polos industriais do EOM. Todavia, todos os 5 municípios obtiveram números acima das 4 mil admissões ao longo dos 11 anos analisados e com obtenções de saldos positivos, demonstrando que mesmo de forma na maioria dos casos, houve um crescimento tímido do emprego na indústria de transformação. Em nossa análise, isso significa que mesmo com a crise, houve no mínimo a manutenção dos patamares de trabalhadores admitidos na indústria de transformação.

O setor de construção teve seu grande boom em Queimados, que correspondeu à maior parte do saldo entre admissões e desligamentos das cinco cidades. A única cidade em que houve retração do setor de construção foi em Paracambi, mas esse setor apresentou uma dinâmica modesta de contratações, o que indica baixa atividade ao longo dos anos analisados. Itaguaí, apesar de um saldo baixo, apresentou um valor muito significativo de admissões no período chegando a um total de 39.698. Esse número indica que houve um período de intensa necessidade de contratação de trabalhadores, mas que essa necessidade se esgotou com o fim das obras.

Denis Castilho, ao tratar das redes e processos espoliativos, afirma que "nunca se viu tantos objetos técnicos, tantas redes e tanta infraestrutura, tampouco tanta exclusividade e tantas pessoas sem acesso a serviços e infraestruturas básicas” (CASTILHO, 2019, p. 295). No capitalismo contemporâneo, da globalização acachapante, de concentração e dispersão, áreas com conexões aos mercados globais convivem ao lado de áreas com precariedade de redes básicas. No Brasil, a partir especialmente de 2016, desde quando vivemos uma profunda crise política e econômica combinada com a queda drástica dos investimentos federais e mudanças nas políticas nacionais com aderência plena ao neoliberalismo - aprovações de teto de gastos públicos e reformas trabalhista e da previdência -, progressivamente assistimos a um país ainda mais desigual e pouco preocupado com disparidades sociais 
A lógica industrial-logística, pensada como ferramenta de modernização e desenvolvimento, não permitiu melhorias significativas da qualidade de vida das populações diretamente impactadas. Ademais, sem uma real integração e participação popular, acabou por se tornar justificativa para a instalação de empreendimentos que beneficiaram apenas determinados setores. A instalação de redes técnicas que viabilizam tais atividades, aprisionadas ao modelo produtivo que espolia os territórios, se não forem pensadas e baseadas na diversificação de suas funções e na democratização do acesso, não cessará com a escalada de destruição e a ampliação das desigualdades (CASTILHO, 2019), algo tão evidente nas cidades do extremo oeste metropolitano do Rio de Janeiro.

\section{Considerações Finais: Provocações acerca de um modelo de desenvolvimento social para a região}

Em meio ao colapso sanitário, econômico e social em decorrência da pandemia da COVID-19 e da necessidade de imunização da população (em meio à adoção desenfreada das práticas neoliberais por parte da Administração Federal), foi anunciada, ainda em 2020, a construção da maior fábrica de vacinas da América Latina, a ser instalada em Santa Cruz num futuro e ambicioso complexo industrial da saúde. Assim, o Distrito Industrial de Santa Cruz abrigará o Complexo Industrial de Biotecnologia em Saúde (CIBS) da Fundação Oswaldo Cruz (Fiocruz), que será o maior centro de produção de produtos biológicos da América Latina e um dos mais modernos do mundo.

O CIBS certamente demandará insumos como frascos, rolhas, tampas, caixas, etc., e isto vem constituindo um novo imaginário de desenvolvimento na região pela atração de novos aportes fabris. As justificativas para o gigantesco projeto na região vão desde a necessidade de vacinação em massa, o fortalecimento do Sistema Único de Saúde e do Plano Nacional de Imunização, mas especialmente a geração de empregos e o almejado desenvolvimento econômico e social, recorrendo às mesmas promessas de momentos anteriores ligados a outros empreendimentos igualmente industriais. Acreditamos que, para que tal promessa se cumpra desta vez, tal complexo precisa ser integrado ao entorno para que possa gerar mais oportunidades de trabalho, capacitação e transbordamentos para a comunidade.

Para além de um simples receituário, entendemos ser possível apresentar alguns elementos circunstanciais para o desenvolvimento social das cidades do Extremo Oeste 
Metropolitano do Rio de Janeiro. Entre as ações balizadoras de possíveis caminhos para o desenvolvimento do EOM, podemos destacar, ainda que de maneira livre e provocadora:

a) A efetivação de planos urbanos e regionais de desenvolvimento mais democráticos, integrados e incisivos, com respostas mais profícuas às necessidades sociais mais imediatas;

b) A constituição de espaços públicos como lugares de (con-)vivência, alimentando o direito à cidade, ao cotidiano e ao encontro; isto significaria repensar as estratégias de contenção de violência urbana e valorizar atividades de integração, mobilização e democratização da urbe;

c) A proposição de maior diálogo com a população que permanece periferizada, respeitando-se as produções locais, como pequenas e médias empresas e as produções agrícolas orgânicas e familiares;

d) O atendimento das necessidades mais básicas da população, que incluem moradia, saneamento básico e saúde - especialmente nesses tempos tão difíceis -, com ampliação dos setores públicos de atendimento; sobre o saneamento básico, é necessário um consórcio entre municípios, estado e União para responder tal questão, bem como buscar o tratamento das águas dos rios que abastecem toda a região metropolitana;

e) A adoção de práticas de produção industriais ecologicamente menos agressivas e mais adequadas a um modelo de sociedade verdadeira sustentável, retirando a proteção ambiental das grades do simples marketing empresarial e combatendo medidas inócuas quando não falaciosas;

f) A criação, manutenção e ampliação de unidades instrucionais, de ensino técnico integrado e educação superior - como a própria UFRRJ -, com protocolos de cooperação com prefeituras e demais entes do Estado, mantendo a autonomia e altivez das intuições de ensino-pesquisa; nesse sentido, a adoção de políticas 
públicas de apoio a jovens profissionais, empreendedores e pequenos empresários que emergem na região se torna fundamental;

g) A consolidação de polos de inovação, não somente técnica, mas especialmente voltada para a inovação social, apontando soluções para os problemas e necessidades regionais, como habitação, saneamento, reflorestamento, agricultura familiar e outros. O Polo do Mar ${ }^{11}$, iniciativa que congrega instituições localizadas no entorno do Porto de Itaguaí, permite vislumbrar uma importante medida que precisa ter como caminho também a inclusão social;

h) A integração modal de passageiros, aproximando a UFRRJ, os Distritos Industriais de Santa Cruz e Queimados, as cidades de Seropédica e Itaguaí das demais cidades da Baixada Fluminense e da cidade do Rio de Janeiro, bem como os municípios da Costa Verde.

Neste aspecto, a integração ferroviária da parte do extremo oeste, que atualmente transporta commodities e permite uma ligação muito intensa e contínua de Itaguaí com o restante do Brasil, necessita transbordar para uma mobilidade ferroviária de passageiros, com a possível edificação de uma Estação Ferroviária Seropédica-UFRRJ, aproveitando os caminhos dos trilhos logísticos existentes para aproximar as populações locais. Afinal, apenas $12 \mathrm{~km}$ separam o entroncamento dos trilhos da MRS (empresa que opera a Malha Regional Sudeste da Rede Ferroviária Federal S. A.) na altura do cruzamento com a BR465 - onde é possível projetar a construção da Estação Ferroviária Seropédica-UFRRJ da estação ferroviária de Japeri. Um esforço público-privado, envolvendo prefeituras, governos estaduais e a esfera federal, e de diferentes sujeitos, como o próprio corpo

\footnotetext{
${ }^{11}$ O Polo do Mar da Baía de Sepetiba tem como intento a promoção do desenvolvimento sustentável da região do entorno da Baía de Sepetiba, por meio de projetos ancorados em três focos principais: Desenvolvimento da Cadeia Produtiva Local, Responsabilidade Social e Negócios Sociais, e Tecnologia, articulando a cooperação para a indução, o fomento, a gestão e a execução de atividades de extensão, projetos de pesquisa científica, desenvolvimento tecnológico e inovação em prol do desenvolvimento socioeconômico sustentável da Baía de Sepetiba, Itaguaí e demais regiões do entorno. Agregando empresas como a ICN, Vale, Porto Sudeste, Nuclep; instituições de Ensino Superior, como a UFRRJ, UERJ (Universidade do Estado do Rio de Janeiro), UEZO (Fundação Centro Universitário Estadual da Zona Oeste), FAETEC (Fundação de Apoio à Escola Técnica); a Secretaria de Estado de Ciência, Tecnologia e Inovação - SECTI RJ; instituições de Pesquisa como a EMBRAPA (Empresa Brasileira de Pesquisa Agropecuária), entre outras, intenciona-se construir parcerias em prol do desenvolvimento socioeconômico regional e do sucesso de projetos inovadores. Ver: https://portal.ufrrj.br/wp-content/uploads/2019/05/Polodo-Mar.pdf. Acesso em: 30 de março de 2021.
} 
técnico da UFRRJ, dos empreendimentos locais e organismos civis, são capazes de projetar não somente a integração Seropédica-Japeri, mas também desenvolver um projeto executivo para uma linha férrea de passageiros capaz de atender Seropédica, Itaguaí e o Distrito Industrial de Santa Cruz, integrando os novos aportes produtivos aos trabalhadores da região.

Segundo estimativa do IBGE, há somente nas cidades de Itaguaí e Seropédica mais de duzentos mil habitantes ávidos pela diversificação dos modais de transportes e que seriam profundamente atendidos com novas formas de mobilidade espacial. Da mesma maneira, a centralidade da Universidade Federal Rural do Rio de Janeiro (UFRRJ), que abriga mais de 14 mil alunos no seu campus-sede, em Seropédica, também se reforçou mediante sua expansão recente, atraindo alunos da região metropolitana e oferecendo capacitações diversas para seus egressos. O movimento pendular intenso de professores, alunos e técnicos justifica a atenção à proposta aqui levantada.

Reforçamos, assim, a leitura territorial do desenvolvimento. O exercício analítico aqui proposto é realizado não somente com base em ferramentas fundamentais de estatística, projeções de investimentos e reverberações em cadeias produtivas, mas executado olhando-se para o território, seus objetos e seus fluxos. Tão importante quando pensarmos nos valores investidos é observar as implicações territoriais, os impactos ambientais, as ações no entorno e os encadeamentos produtivo-espaciais. E o território não é tão somente um mapa aberto sobre a mesa de decisões - ainda que isto também seja fundamental -, mas é o espaço animado por pessoas que moram, trabalham, estudam, se divertem e lutam na expectativa de um desenvolvimento mais inclusivo.

\section{REFERÊNCIAS}

BOITO JÚNIOR, Armando. As bases políticas do neodesenvolvimentismo. PIMSA Documentos y comunicaciones, 2013-2014, n. ${ }^{\circ} 15,2015$, p. 209-226.

BOTELHO, Maurilio Lima. Crise urbana no Rio de Janeiro: favelização e empreendedorismo dos pobres. In: Brito, Felipe; Oliveira, Pedro Rocha de. (OrgS.). Até o último homem: visões cariocas da administração armada da vida social. São Paulo: Boitempo, 2013, v. 1, p. 169-213.

BOTELHO, Maurílio Lima. Teoria da Crise em David Harvey: observações sobre Os Limites do Capital. Revista Continentes (UFRRJ), Rio de Janeiro, ano 3, n.4, 2014, p. 66-111. 
https://www.revistacontinentes.com.br/index.php/continentes/article/view/40. Acesso 15 mar. 2020

CAGED - Cadastro Geral de Empregados e Desempregados. Ministério do Trabalho. Brasil. Disponível em http://pdet.mte.gov.br/caged. Acesso em: 13 mar. 2021.

CANDIDO, D'Jeanine. As transformações espaciais resultantes da inserção de redes técnicas em São Gonçalo: o Sistema UHOS (Ultra Heavy Over Size) e a sua refuncionalização com o projeto Cidade da Pesca. Espaço e Economia [Online], 15, 2019. Disponível em: http://journals.openedition.org/espacoeconomia/7063. Acesso em: 13 mar. 2021.

CAPETTI, Pedro. País não cria vagas com ganhos acima de 2 salários mínimos há 14 anos. O Globo, dia 25/01/2020. Disponível em: https://oglobo.globo.com/economia/paisnao-cria-va-gas-com-ganhos-acima-de-2-salarios-minimos-ha-14-anos-24211895.

Acesso em: 10 jan. 2021.

CARVALHO, Laura. Valsa Brasileira: Do bom ao caos econômico. São Paulo: Todavia, 2018.

CASTILHO, Dênis. Redes e processos espoliativos no Centro-Norte do Brasil. In:

OLIVEIRA, Floriano Godinho de; OLIVEIRA, Leandro Dias de; TUNES, Regina Helena; PESSANHA, Roberto Moraes (Orgs.). Espaço e economia: geografia econômica e a economia política. Rio de Janeiro: Consequência, 2019, p. 295-320.

DAMAS, Eduardo Tavares. Distritos industriais da cidade do Rio de Janeiro: gênese e desenvolvimento no bojo do espaço industrial carioca. 2008. 143f. Dissertação (Mestrado em Geografia) - Universidade Federal Fluminense, Niterói, 2008.

GALA, Paulo. Complexidade econômica: uma nova perspectiva para entender a antiga questão da riqueza das nações. Rio de Janeiro: Contraponto: Centro Internacional Celso Furtado de Políticas para o Desenvolvimento, 2017.

GERMANO, André Luiz do Nascimento. Novo Desenvolvimentismo Brasileiro: a atuação da Ternium CSA - Companhia Siderúrgica do Atlântico, em Santa Cruz, Rio de Janeiro - RJ. 2020. Dissertação (Mestrado em Geografia) - Universidade Federal Rural do Rio de Janeiro, 2020.

IBGE Cidades. Disponível em: https://cidades.ibge.gov.br. Acesso em: 20 mar. 2021.

LENCIONI, Sandra. Urbanização difusa e a constituição de megarregiões: O caso de São Paulo-Rio de Janeiro. E-metropolis: Revista Eletrônica de Estudos Urbanos e Regionais, ano 6, n. ${ }^{\circ}$ 22, setembro de 2015. Disponível em: http://www.emetropolis.net/index.php?option=com_edicoes\&task=artigos\&id=132\&lan $\mathrm{g}=\mathrm{pt}$. Acesso em: 05 mar. 2021.

MASCARENHAS, Gilmar. Cidade mercadoria, cidade-vitrine, cidade turística: a espetacularização do urbano nos megaeventos esportivos. Caderno Virtual de Turismo 
(UFRJ), v. 14, p. 52-65, $2014 . \quad$ Disponível em: http://www.ivt.coppe.ufrj.br/caderno/index.php/caderno/article/view/1021 . Acesso em: 30 mar.2021.

MASCARENHAS, Gilmar; BIENENSTEIN, Glauco; SANCHEZ, Fernanda (Orgs.). O Jogo continua: Megaeventos esportivos e cidades. Rio de Janeiro: EDUERJ / FAPERJ, 2011.

MASCARENHAS, Gilmar; OLIVEIRA, Leandro Dias de; RAMÃO, Felipe de Souza. Urbanização turística e produção do espaço na cidade de Cabo Frio - RJ: um balanço crítico (1997-2018). Revista Tamoios, v. 16, p. 15-28, 2020. Disponível em: http://https://www.e-publicacoes.uerj.br/index.php/tamoios/article/view/45750/34170.

Acesso em: 30 mar. 2021.

MERCADANTE, Aluízio. As bases do Novo Desenvolvimentismo: análise do governo Lula. Tese (Doutorado em Economia), Programa de Pós-Graduação em Ciência Econômicas, Instituto de Economia, UNICAMP - Universidade Estadual de Campinas, 2010.

MOURA, Iara; RODRIGUES, Isabelle. A realidade por trás da Ternium. Le Monde Diplomatique Brasil, 2018. Disponível em: https://diplomatique.org.br/a-realidade-portras-da-ternium-brasil/\&gt. Acesso em: 24 out. 2020.

OLIVEIRA, Floriano José Godinho de. Investimentos produtivos, territorialidades e gestão do uso do território no leste metropolitano do Rio de Janeiro In: BINSZTOK, Jacob e BARBOSA, Jorge Luiz (org.). Modernização fracassada: Dossiê Comperj. Rio de Janeiro: Consequência, 2018.

OLIVEIRA, Floriano José Godinho de; OLIVEIRA, Leandro Dias de. Espaço metropolitano, regionalização da economia e reestruturação produtiva no estado do Rio de Janeiro, Brasil. Cuyonomics. Investigaciones En Economía Regional, 3(5), 39-65, $2020 . \quad$ Disponível em: http://revistas.uncu.edu.ar/ojs/index.php/cuyonomics/article/view/3601. Acesso em: 12 mar. 2021.

OLIVEIRA, Leandro Dias de. A emersão da região logístico-industrial do Extremo Oeste Metropolitano fluminense: reflexões sobre o processo contemporâneo de reestruturação territorial-produtiva. Espaço e Economia [Online], 7, 2015. Disponível em: http://journals.openedition.org/espacoeconomia/1814. Acesso em: 25 mar. 2021.

OLIVEIRA, Leandro Dias de. Seropédica Sustentável: Transformações ecológicoeconômico-espaciais recentes em um lacônico julgamento. Recôncavo Revista de História da UNIABEU, v. 6, p. 87-101, 2016. Disponível em: http://www.uniabeu.edu.br/publica/index.php/reconcavo/article/view/2562/pdf. Acesso em: 25 mar. 2021.

OLIVEIRA, Leandro Dias de. Ecologia política, reestruturação territorial-produtiva e desenvolvimento sustentável no Brasil: lições do extremo oeste da Região Metropolitana 
do Rio de Janeiro. Espaço e Economia [Online], 19 | 2020. Disponível em: http://journals.openedition.org/espacoeconomia/16203. Acesso em: 25 mar. 2021.

OLIVEIRA, Leandro Dias de. Para além da capital: os eixos geográficos de dispersão da pandemia no estado do Rio de Janeiro. OpenLab / PPGIHD-UFRRJ, 2020a. Disponível em: https://www.ppgihd-open-lab.com/post/para-al\%C3\%A9m-da-capital. Acesso em: 25 mar. 2021.

PACS. Companhia Siderúrgica do Atlântico - TKCSA: Impactos e Irregularidades na Zona Oeste do Rio de Janeiro. PACS, $2^{a}$ edição, 2009.

PACS. Companhia Siderúrgica do Atlântico - TKCSA: Impactos e Irregularidades naZona Oeste do Rio de Janeiro. PACS, 3a edição, 2012.

PERDIGÃO, Isis Alves do Sacramento. Os investimentos financeiros na região da Baía de Sepetiba e as articulações com o desenvolvimento territorial: uma breve nota. XVI ENANPUR, Belo Horizonte, 2015.

PESSANHA, Roberto Moraes. A relação transescalar e multidimensional "PetróleoPorto" como produtora de novas territorialidades. $560 \mathrm{f}$. Tese (Doutorado em Políticas Públicas e Formação Humana), Programa de Pós-Graduação em Políticas Públicas e Formação Humana, Universidade do Estado do Rio de Janeiro, 2017.

PESSANHA, Roberto Moraes; Gomes Filho, Hélio; QUINTO JÚNIOR, Luiz Pinedo; SILVA NETO, Romeu; OLIVEIRA. Floriano Godinho. A Gênese do Complexo Logístico Industrial Porto do Açu: oportunidades e desafios para o desenvolvimento da Região Norte Fluminense. Revista Brasileira de Gestão e Desenvolvimento Regional, v. $10, \quad$ n. $2, \quad$ jun. 2014. Disponível em: https://www.rbgdr.net/revista/index.php/rbgdr/article/view/1355. Acesso em: 25 mar. 2021.

PINHO, Miguel Alexandre do Espirito Santo. A miragem do desenvolvimento na periferia metropolitana: reestruturação e crise em Queimados - RJ. 2021. Dissertação (Mestrado em Geografia) - Universidade Federal Rural do Rio de Janeiro, 2021.

POCHMANN, Marcio. Desenvolvimento e perspectivas novas para o Brasil. São Paulo: Cortez, 2010.

ROCHA, André Santos. As representações ideais de um território: Dinâmica econômica e política, agentes e a produção de novos sentidos na apropriação territorial da Baixada Fluminense pós 1990. Tese (Doutorado em Geografia), PPGG - Programa de Pós-Graduação em Geografia, UFRJ - Universidade Federal do Rio de Janeiro, 2014.

SANTOS, Milton; SILVEIRA, María Laura. O Brasil: Território e sociedade no início do século XXI. $18^{\text {a }}$ ed. São Paulo: Record, 2001.

SOJA, Edward W. Geografias Pós-Modernas: A reafirmação do espaço na teoria social críticia. Rio de Janeiro: Jorge Zahar Editora,1993 [1989]. 
SOUZA, Jessé. A elite do atraso: da escravidão à Lava Jato. Rio de Janeiro: Leya, 2017.

TINOCO, Victor. O Arco Metropolitano do Rio de Janeiro: modernização, acumulação e novo desenvolvimentismo. Espaço e Economia [Online], 14 | 2019. Disponível em: http://journals.openedition.org/espacoeconomia/6136. Acesso em: 30 mar. 2021. 